\title{
The Chronic Effects of Copper and Cadmium on Life History Traits Across Cladocera Species: A Meta-analysis
}

\author{
Shlair A. Sadeq ${ }^{1}$. Andrew P. Beckerman ${ }^{1}$
}

Received: 13 March 2018 / Accepted: 27 August 2018 / Published online: 3 September 2018

(c) The Author(s) 2018

\begin{abstract}
The effect of sublethal concentrations of heavy metals on cladoceran growth and reproduction is a cornerstone of modern ecotoxicology. However, the literature contains assays across numerous concentrations, on numerous species and genotypes, and conditions are far from consistent. We undertook a systematic review of the sublethal effects of copper and cadmium concentrations on Cladocera spp. life history (reproduction, maturation age, and somatic growth rate). Using meta-analysis, we tested the hypothesis that the effects of increasing $\mathrm{Cu}$ and $\mathrm{Cd}$ concentrations on traits may vary by species. We also evaluated where possible whether the effect of metal concentrations on traits vary by water hardness, exposure duration, or whether the metals were delivered in aqueous solution or via food. We surveyed $>200$ papers, resulting in a set of 32 experimental studies representing 446 trials where the results were presented compared with Daphnia magna-the most commonly assayed species. We found qualitatively similar effects of $\mathrm{Cu}$ and $\mathrm{Cd}$ on life history traits that included reduction in reproduction and somatic growth rate and delay of maturation. Cladocera species showed marked variations in their susceptibility to metals, and D. magna was found to be the least sensitive species to sublethal changes in reproduction. The effects were largely consistent for aqueous vs. dietary food. Water hardness, where data were available, had no detectable effect. Available data indicate that exposure duration had no effect on the toxicity of $\mathrm{Cu}$ but did for $D$. magna reproductive response to $\mathrm{Cd}$. Our study highlights the importance of including species identity when considering toxicological testing and regulation development.
\end{abstract}

Anthropogenic and natural processes introduce a great deal of pollutants and stress into natural ecosystems (Mountouris et al. 2002; Demirak et al. 2006; Dedourge-Geffard et al. 2009; Martins et al. 2017). Over the past few decades, trace levels of metals have received much attention (Jing et al. 2006), because they generate negative biological effects on aquatic organisms, such as algae grazers and subsequently alter water quality. Such "sublethal" effects include changes in reproduction (Bodar et al. 1988a; Wang et al. 2009; Kim et al. 2017), somatic growth rate (Chandini 1989; Koivisto et al. 1992; De Schamphelaere and Janssen 2004a), feeding rate (Ferrando and Andreu 1993; MacWilliam and Baird

Electronic supplementary material The online version of this article (https://doi.org/10.1007/s00244-018-0555-5) contains supplementary material, which is available to authorized users.

Shlair A. Sadeq

sasadeq1@ sheffield.ac.uk

1 Department of Animal and Plant Sciences, University of Sheffield, Alfred Denny Building, Western Bank, Sheffield S10 2TN, UK
2002; De Schamphelaere et al. 2007), and respiration and metabolism (Dave 1984; Bodar et al. 1988b; Khangarot and Rathore 2003).

Copper and cadmium are widely found as pollutants in natural water systems and are well-known toxicants for aquatic invertebrates, particularly Cladocera. These chemicals continue to occupy a large portion of the research agenda on sublethal effects of metal pollution (Bellavere and Gorbi 1981; Shuhaimi-Othman et al. 2010; FernándezGonzáles et al. 2011). However, each element has a different mode of action (Shanker 2008). $\mathrm{Cu}$ is an essential element to living organisms where it is primarily involved as a co-factor in enzymatic reactions of biological processes (Bossuyt and Janssen 2004; de Oliveira-Filho et al. 2004). It is considered to be a potent toxicant only at high concentrations and works largely by disrupting digestive physiology, which is linked to energy intake and hence resources acquired for growth and reproductive activities (Barata and Baird 2000; Bui et al. 2016). Its toxicity at high concentrations derives from its redox potential where it can induce reactive oxygen species formation (ROS) that lead to oxidative stress (Stoddard and 
Harper 2007; Giusto and Ferrari 2014). These conditions can cause damage to biological structures, such as DNA, lipoproteins, and organelles (Letelier et al. 2005; Giusto and Ferrari 2014). Furthermore, it has been demonstrated that $\mathrm{Cu}$ inhibits the activity of enzymes involved in cell metabolism, such as $\mathrm{Na}^{+} / \mathrm{K}^{+}$-ATPase and $\mathrm{Mg}^{+2}$-ATPase, which are responsible for the exchange of ions across the cell membrane (Pagliarani et al. 1996; Handy et al. 2002; Katranitsas et al. 2003).

On the other hand, $\mathrm{Cd}$ is a nonessential element and highly toxic even at very low concentrations (Gama-Flores et al. 2006; Wang et al. 2009). The International Agency for Research on Cancer of USA (1997) classified cadmium as a Type 1 carcinogen. Exposure causes a series of changes in cellular homeostasis, such as DNA damage, acidification of the cytoplasm, and oxidative stress linked to ROS formation via elevation of lipid peroxidation in tissues (Stohs and Bagchi 1995; Soetaert et al. 2007). In addition to its role in reduction of the activity of antioxidant enzymes, such as glutathione peroxidase (GPx), catalase (CAT), and superoxide dismutase (SOD) (Waisberg et al. 2003; Wang et al. 2004; Sandrini et al. 2008). Cd also strongly impacts feeding activity which hence impairs reproduction and growth (Baird et al. 1990; Barata and Baird 2000). In freshwater systems, the concentrations associated with sublethal effects for $\mathrm{Cu}$ range from 0.2 to $30 \mu \mathrm{g} / \mathrm{L}$ (Al-Reasi et al. 2012), whereas it is lower than $0.1 \mu \mathrm{g} / \mathrm{L}$ for Cd (Tan and Wang 2011).

In natural environments, contaminants often are diluted and occur at low concentrations. Therefore, aquatic organisms are considered to be under risk of chronic exposure to low concentrations over long periods. To evaluate the risks associated with pollutants, chronic exposure to sublethal concentrations of a stressor is typically used to examine life history responses of different species. Furthermore, shortterm toxicity tests represent an early warning indicator of toxicant impacts on aquatic organisms (Stephan et al. 1985). These ecotoxicological assays are a typical method for evaluating how an organism or a population respond to contaminants exposure (Barata and Baird 2000). The data from such assays are used to define standards for ecosystem services, such as water quality monitoring, and to define impacts on natural populations, their habitats, and ecosystems (Lopes et al. 2004; Cooper et al. 2009).

Recent work suggests that the responses to sublethal concentrations of metals may be influenced by species identity (e.g., interspecific variation) and genotype (e.g., intraspecific variation) (Barata et al. 2000; Hoang and Klaine 2007). Furthermore, metal complexity, metal toxicity, and aqueous versus dietary exposure influencing bioavailability to an organism may be important (Gusso-Choueri et al. 2012). This may be further influenced by redox potential, $\mathrm{pH}$, hardness, and the amount of existing metal present in water (Long et al. 2004; Bae and Freeman 2007; Hoang and Klaine 2007).
It has been demonstrated that bioavailability and toxicity of metals to aquatic species may be affected by a number of environmental factors, such as water hardness, alkalinity, $\mathrm{pH}$, and dissolved organic carbon (DOC) (Santore et al. 2001). The biotic ligand model (BLM) is a promising model to assess how the water chemistry influence the toxicity of $\mathrm{Cu}$ to Daphnia magna. This model is based on the complexation of free ions and competition with other cations (from the natural and artificial media) (Bossuyt et al. 2004; De Schamphelaere and Janssen 2004b, c; De Schamphelaere et al. 2004; Clifford and McGeer 2010). Data collected from the literature agree on the decrease of $\mathrm{Cu}$ toxicity as a result of hardness, $\mathrm{pH}$, and dissolved organic carbon (Di Toro et al. 2001; Santore et al. 2001; De Schamphelaere et al. 2004). Furthermore, BLM has recently been developed for other metals across species of invertebrates, including Daphnia (Keithly et al. 2004; De Schamphelaere et al. 2006; Kozlova et al. 2009; Clifford and McGeer 2010; Esbaugh et al. 2012).

Toxicity tests on a species level (single and multiple) remain the core biological level of assessment, and it is assumed that the link between ecosystems function and taxonomic variation in the response to toxicants can offer insight into how population and ecosystems may respond (Cairns 1983; Rahbek 2005). This is crucial in the context of ecotoxicology where very few species or even taxa are used to make inference about the environmental impacts of contaminants and other stressors. Whilst species differences may seem to be "common sense," identifying such differences should provide important insight into how the evaluation of toxicant impacts is conducted. Although environmental risk assessment routinely focuses on responses of one or several species to chemicals, little is known regarding species specificity in life history responses under short- or long-term exposure.

The cladoceran species are regarded as the ideal model for ecotoxicological tests of monitoring natural ecosystems. They have a global distribution, play a central role in the aquatic food chain, are sensitive to a vast range of pollutants, are easy to handle, have a short lifespan, and demonstrate dramatic phenotypic plasticity (Lampert 2006; Stollewerk 2010). Considerable laboratory research has documented effects of sublethal concentrations of $\mathrm{Cu}$ and $\mathrm{Cd}$ on life history traits of different species of Cladocera (Baird et al. 1990; Khangarot and Rathore 2003; Sofyan et al. 2007; Dao et al. 2017) (Fig. 1). However, to date, we are unaware of any systematic review of this literature that would allow estimation of whether the effect of increasing $\mathrm{Cu}$ or $\mathrm{Cd}$ concentration on life history varies by species, how experimental conditions affect these responses, and which species demonstrate strong or weak responses (e.g., appear resistant or sensitive). 
Fig. 1 Number of studies for each species of Cladocera in response to subchronic exposure of $\mathrm{Cu}$ and $\mathrm{Cd}$

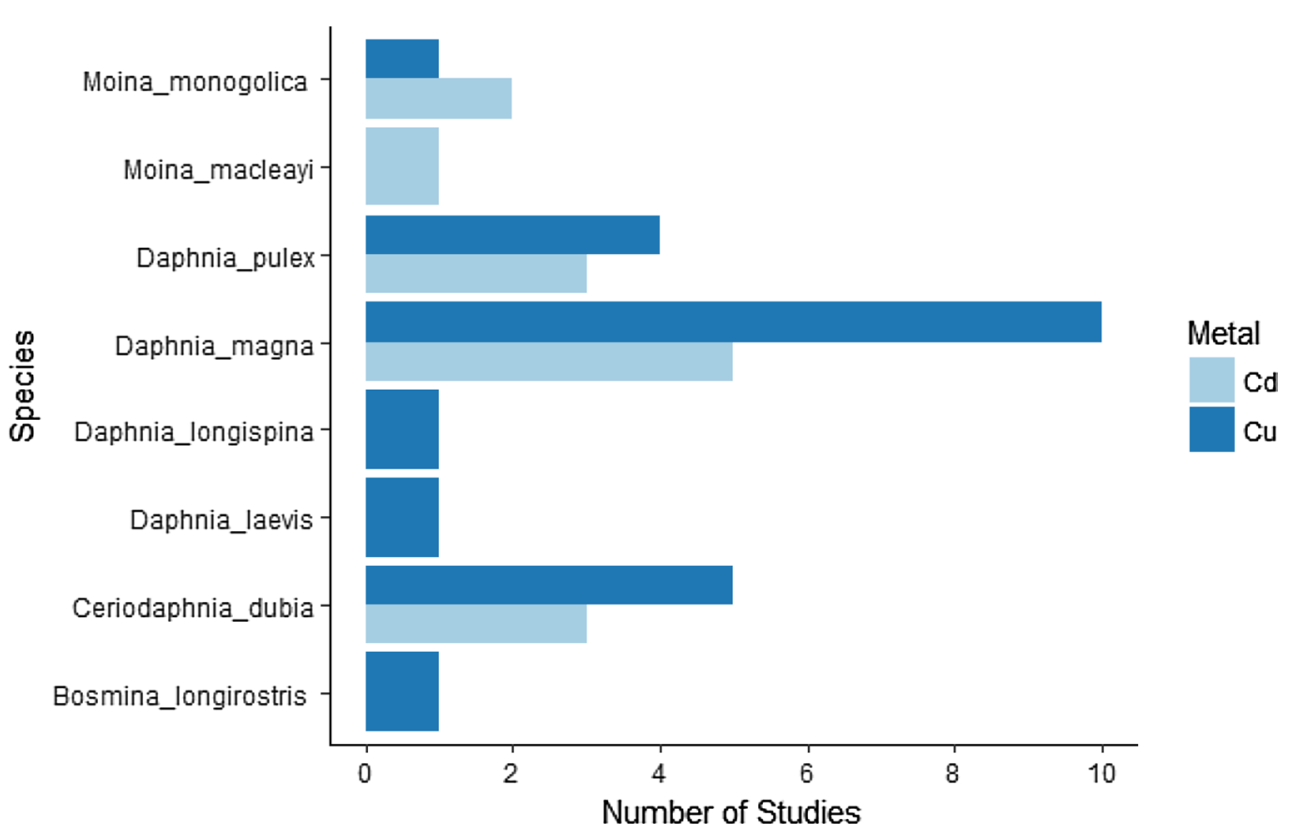

\section{Expectations from Theory}

Existing research centers on several aspects of Daphnia spp. behavior and life history: feeding rates, the number of neonates per female per day, age at maturity, and somatic growth rate. Life history theory provides a template against which the effects of $\mathrm{Cu}$ and $\mathrm{Cd}$ can be evaluated. Because they interfere with digestion, acting to limit resource intake and assimilation (De Coen and Janssen 1997; Lv et al. 2017), and ultimately interfere with metabolism (De Coen and Janssen 1998), life history theory predicts that as metal concentrations rise, foraging, and assimilation of energy may decline leading to reduced reproduction, delayed maturity, and slower somatic growth rates.

However, data reviewed on a case by case basis provide equivocal alignment with such expectations. While many published data showed that $\mathrm{Cu}$ and $\mathrm{Cd}$ have negative impacts on the production of neonates in many species (Knops et al. 2001; Luciana et al. 2014), feeding rate (MacWilliam and Baird 2002), and somatic growth rate (Agra et al. 2011), several studies also demonstrated that each metal can cause an increase in neonate production (Dave 1984; Bodar et al. 1988a; Roux et al. 1993; Agra et al. 2011).

Thus, while theory predicts marked changes in life history, there are equivocal empirical patterns among studies and species requiring meta-analytic tools to make cross study inference. The objective of our systematic review is to analyze the effects of $\mathrm{Cu}$ and $\mathrm{Cd}$ across studies, capturing variation in both species identity and specific lab conditions that might generate variation in the responses to metals.

First, we asked whether increasing $\mathrm{Cu}$ or $\mathrm{Cd}$ concentrations lead to decreased reproduction, delayed maturity and slower somatic growth rates, and whether this varies by species. Second, where possible, we tested whether aqueous versus dietary $\mathrm{Cu}$ and $\mathrm{Cd}$ induced different responses among Daphnia species. Finally, where possible, we considered whether lab conditions, including water hardness and exposure period, interact with $\mathrm{Cu}$ and $\mathrm{Cd}$ toxicity on life history parameters. Overall, species identity matters substantially; the most common species studied (Daphnia magna) appeared to be more resistant (i.e. less sensitive) to metals than other species.

\section{Materials and Methods}

\section{Literature Search}

We gathered evidence from the literature on the effect of sublethal $\mathrm{Cu}$ and $\mathrm{Cd}$ on the number of neonates per female per day, age at maturity, and somatic growth rate in different species of Cladocera. We searched in seven databases: Web of Science, Scopus, JSTOR, BIOSIS, ScienceDirect, Google Scholar and StarPlus (University of Sheffield library collection) for relevant publications, using the following key word combinations: (effect OR impact* OR influence*) AND (metals OR copper* OR cadmium*) AND (life history OR reproduction* OR age at maturity* OR growth rate*) AND (Daphnia OR Cladocera*). We collected studies between 1970 and 2017.

More than 200 references were obtained that measured relevant endpoints under chronic exposure of $\mathrm{Cu}$ and $\mathrm{Cd}$. However, to be included, studies must report accessible information on the mean, standard deviation, or standard error of effects and sample sizes (Vilá et al. 2011). Publications were excluded when any of this information was 
missing or not estimable from the information provided. Only 32 of $>200$ papers reported all data required for each trait/metal.

\section{Data Extraction and Effect Size Calculation}

For each study, quantitative data was extracted on metal type $(\mathrm{Cu}, \mathrm{Cd})$, species identity, traits (reproduction, maturation age, and somatic growth rate), aqueous or dietary delivery of the metal, exposure duration, water hardness, and the sample size, standard deviations or standard errors, and the mean of both the control and the experimental groups. These data were obtained directly from tables or digitized from graphs or bars using Graph-Click (Arizona Software, version 3.0.3). Where necessary, we calculated the standard deviation by multiplying the standard error by the square root of the sample size.

We performed a quantitative meta-analysis focusing on whether the effect of the metals varied by species. We also explored the effects of delivery method, exposure duration and water hardness. These analyses were conducted using Osenberg et al. (1997) method allowing comparisons among studies. For each trait and trial, we calculated Cohen's $d$ according to the following equation:

$d=\frac{X_{\mathrm{e}}-X_{\mathrm{c}}}{s} J$

where $X_{\mathrm{c}}$ is the mean of the control group, $X_{\mathrm{e}}$ is the mean of the experimental group and $s$ is the pooled standard deviation of the control and experimental groups, and $J$ is the corrector for bias.

$s=\sqrt{\frac{\left(N_{\mathrm{e}}-1\right)\left(S_{\mathrm{e}}\right)^{2}+\left(N_{\mathrm{c}}-1\right)\left(S_{\mathrm{c}}\right)^{2}}{\left(N_{\mathrm{e}}+N_{\mathrm{c}}-2\right)}}$

$J=1-\frac{3}{4\left(N_{\mathrm{e}}-N_{\mathrm{c}}-2\right)-1}$

$S_{\mathrm{e}}$ is the standard deviation of the experimental group, $S_{\mathrm{c}}$ is the standard deviation of the control group, $N_{\mathrm{e}}$ is the number of cases of the experimental group, and $N_{\mathrm{c}}$ is the number of cases of the control group.

The primary goal of our study was to identify the species specificity of the effects of nominal concentrations of $\mathrm{Cu}$ and $\mathrm{Cd}$ on reproduction, maturation age, and somatic growth rate. Where possible, we evaluated whether an aqueous versus dietary source of food influenced this pattern and whether water hardness and exposure period influenced this pattern. To assess the overall significance of an interaction between concentration and species OR concentration and condition, we fit random effects models using maximum likelihood via the Metafor package in R (Viechtbauer 2010;
R Core team 2013) version 1.1.453. We performed a likelihood ratio test (LRT) between a model with and without the interaction between metals and species to test formally whether the effect of $\mathrm{Cu}$ and $\mathrm{Cd}$ on traits varied by species/ experimental conditions. Regression coefficients were then evaluated on the model using restricted maximum likelihood. Furthermore, D. magna was the most common species reported in the literature, and we present specific inference about the interactions (or lack of) via comparison to the $D$. magna response (reference species).

\section{Results}

We first report whether the effect of aqueous $\mathrm{Cu}$ and $\mathrm{Cd}$ concentration on traits depend on species. This includes comparing aqueous versus dietary delivery. We then report on the experimental factors of water hardness and exposure duration.

\section{Copper-Reproduction: Aqueous and Dietary Delivery}

Of the 12 independent studies reporting on aqueous $\mathrm{Cu}$ concentration and reproduction, 95\% reported a nominal concentration between 0 and $120 \mu \mathrm{g} / \mathrm{L}$. A total of 161 trials provide data on effect of $\mathrm{Cu}$ concentration on reproduction among four species of Cladocera: Daphnia magna, D. longispina, Moina monogolica, and Ceriodaphnia dubia.

Overall, increasing $\mathrm{Cu}$ concentration led to a decrease in the mean number of neonates produced per female per day and the effects of copper on reproduction varied by species (Fig. 2; LRT $=19.76, p=0.0002$ ). As Cu concentration increased, $D$. magna reproduction declined (D. magna slope $=-0.04, z=-8.8, p=0.0001$, intercept $=0.64, z=2.6$, $p=0.009)$. The effect of $\mathrm{Cu}$ on C. dubia was indistinguishable from D. magna (gradient change from D. magna $=0.015$, $z=0.95, p=0.34$ ). By comparison, $\mathrm{Cu}$ had a weaker effect on D. longispina (gradient change from D. magna $=0.05$, $z=2.8, p=0.005$ ), reflecting a slightly positive effect of $\mathrm{Cu}$ for this species. $\mathrm{Cu}$ had an even stronger negative effect on M. monogolica (gradient change from D. magna $=-0.19$, $z=-3.3, p=0.001)$.

In the subset of data that documents the effect of dietary $\mathrm{Cu}(\leq 120 \mu \mathrm{g} / \mathrm{L}),$,19 trials present data across three studies of two species of Cladocera: D. magna and C. dubia. We found that the effect of $\mathrm{Cu}$ concentration on reproduction does not vary by species (Fig. 3a; LRT $=2.66, p=0.102$ ). $\mathrm{Cu}$ increased $D$. magna reproduction (D. magna intercept $=1.96, z=2.21, p=0.027)$, but the concentration had no effect $(D$. magna slope $=-0.02, z=-1.82, p=0.067)$. The effect of $\mathrm{Cu}$ on $C$. dubia was to reduce reproduction on average (difference in intercept to D. magna $=2.86, z=4.54$, 


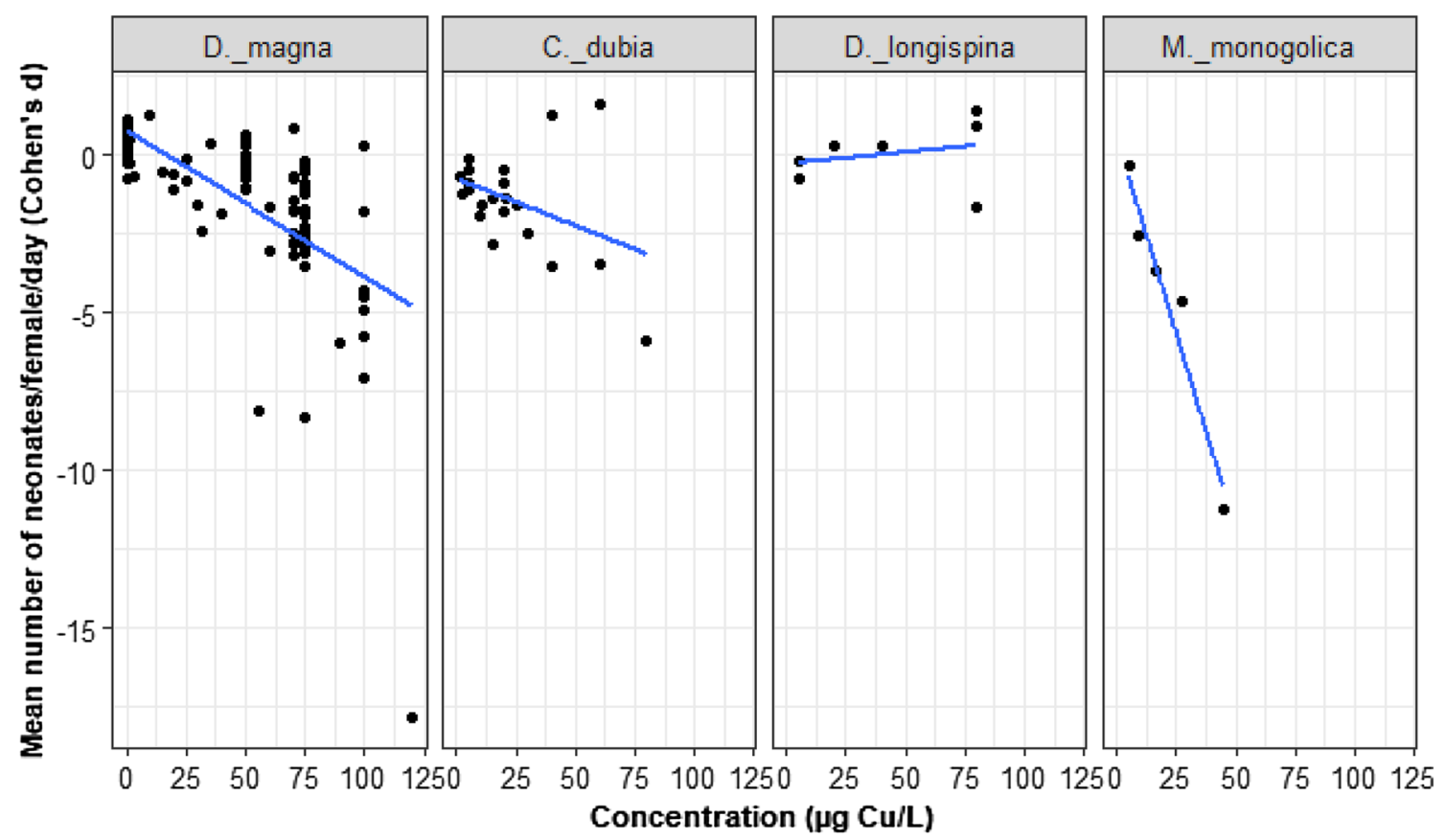

Fig. 2 Mean number of neonates produced per female per day for four species of Cladocera exposed to $\leq 120 \mu \mathrm{g} / \mathrm{L}$ (nominal aqueous concentrations of $\mathrm{Cu}$ ). The black dots represent $d$ values, $n=161$. All

$p=0.0001)$. For dietary $\mathrm{Cu}$, concentrations $\geq 120 \mu \mathrm{g} / \mathrm{L}$ had a strong negative effect, with data only available for $D$. magna reproduction, strongly driven by a single trial (from one study) at $500 \mu \mathrm{g} / \mathrm{L} \mathrm{Cu}$ (Fig. 3b).

\section{Copper-Age at Maturity}

Our meta-analysis for age at maturity included 41 trials of four independent studies. All data are referenced to reported nominal $\mathrm{Cu}$ concentrations and involve four species: $D$. magna, D. pulex, Bosmina longirostris, and D. longispina. Increasing copper concentration delayed maturation and this effect varied by species (Fig. 4 ; LRT $=9.56, p=0.022$ ). For D. magna, increasing $\mathrm{Cu}$ concentration delayed the maturation age (D. magna slope $=0.08, z=3.10, p=0.001$, intercept $=-0.66, z=-1.22, p=0.022)$. The effects of $\mathrm{Cu}$ concentration on maturation age for both $D$. pulex (gradient change from D. magna $=-0.04, z=-0.77, p=0.436$ ) and B. longirostris (gradient change from D. magna $=0.005$, $z=0.06, p=0.951$ ) were not different from $D$. magna. By contrast, increasing $\mathrm{Cu}$ concentration delayed less severely the maturation age of $D$. longispina (gradient change from D. magna $=-0.07, z=-2.77, p=0.005)$.

\section{Copper-Somatic Growth Rate}

Our meta-analysis of somatic growth rate involved 7 studies providing 69 trials among 3 species: D. magna, D. species are compared to the reference species (first panel). Only $D$. magna has a range of $\mathrm{Cu}$ concentrations up to $\leq 120 \mu \mathrm{g} / \mathrm{L}$

longispina, and D. laevis. The effect of $\mathrm{Cu}$ concentration on somatic growth rate depends on species (Fig. 5; $\mathrm{LRT}=8.26, p=0.016)$. With increasing $\mathrm{Cu}$ concentrations, the somatic growth rate decreased for D. magna ( $D$. magna slope $=-0.07, z=-6.7, p=0.0001$, intercept $=0.17$, $z=0.61, p=0.54)$. The effect of $\mathrm{Cu}$ concentration on the somatic growth rate of $D$. laevis was not different from $D$. magna (gradient change from D. magna $=-0.03, z=-0.47$, $p=0.64)$. The effect of $\mathrm{Cu}$ concentration also reduced the $D$. longispina somatic growth rate but significantly less than for D. magna (gradient change from D. magna $=0.053, z=2.72$, $p=0.006)$.

\section{Cadmium-Reproduction: Aqueous and Dietary Delivery}

Seventy-two trials from ten studies were available to explore the effects of $\mathrm{Cd}$ on reproduction in three species: D. magna, M. monogolica, and C. dubia. Ninety-five percent of the studies reported nominal concentration between 0 and $40 \mu \mathrm{g} / \mathrm{L} \mathrm{Cd}$.

For aqueous Cd delivery, we analyzed 40 trials from 6 studies. Increasing $\mathrm{Cd}$ concentration reduced reproduction, but this did not vary by species (Fig. 6a; LRT $=2.39$, $p=0.30$ ). As Cd concentration increased, D. magna reproduction decreased (D. magna slope $=-0.097, z=-2.84$, $p=0.004$, intercept $=-0.50, z=-2.02, p=0.043)$. The average effects of $\mathrm{Cd}$ on reproduction on $C$. dubia (difference 

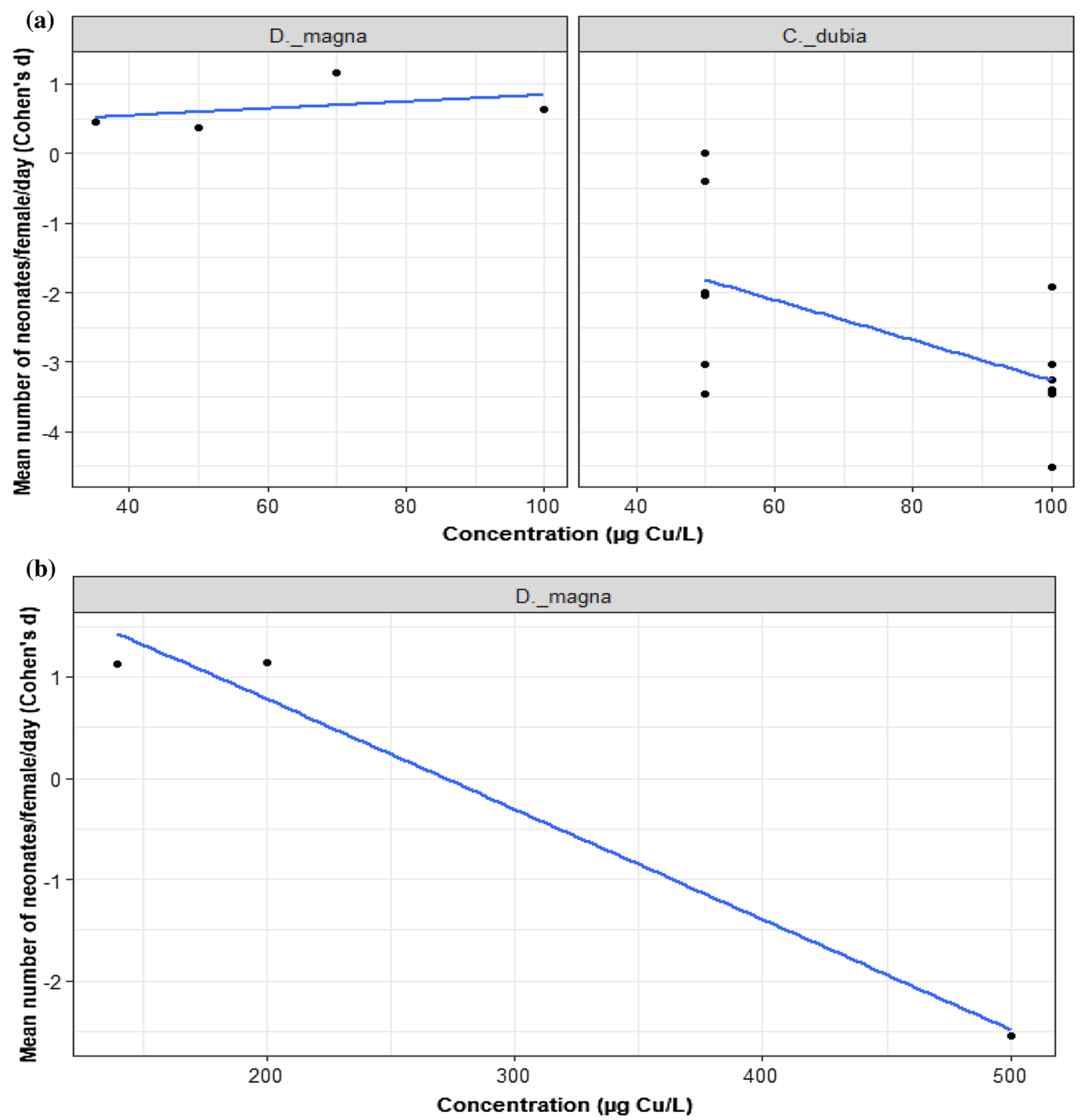

Fig. 3 Mean number of neonates produced per female per day for a two species of Cladocera exposed to $\leq 120 \mu \mathrm{g} / \mathrm{L}$ dietary $\mathrm{Cu}$ (nominal), the black dots represent $d$ values, $n=16$, b $D$. magna exposed to
$>120 \mu \mathrm{g} / \mathrm{L}$ dietary $\mathrm{Cu}$ (nominal), $n=3$. All species are compared to the reference species (D. magna)

$z=-0.44, p=0.66)$. Cd concentration also did not reduce $C$. dubia reproduction compared with $D$. magna (gradient change from $D$. magna $=-0.13, z=-1.78, p=0.074$; note influential data point at $80 \mu \mathrm{g} / \mathrm{L} \mathrm{Cd}$ ). The effect of Cd concentration on $M$. monogolica also was not different from D. magna (gradient change from D. magna $=0.05$, $z=0.72, p=0.47)$. However, the effect of Cd concentration on $C$. dubia was very different to M. monogolica (gradient change $C$. dubia to M. monogolica $=0.18, z=3.57$, $p=0.003)$. This difference drives the interaction between $\mathrm{Cd}$ concentration and species. 

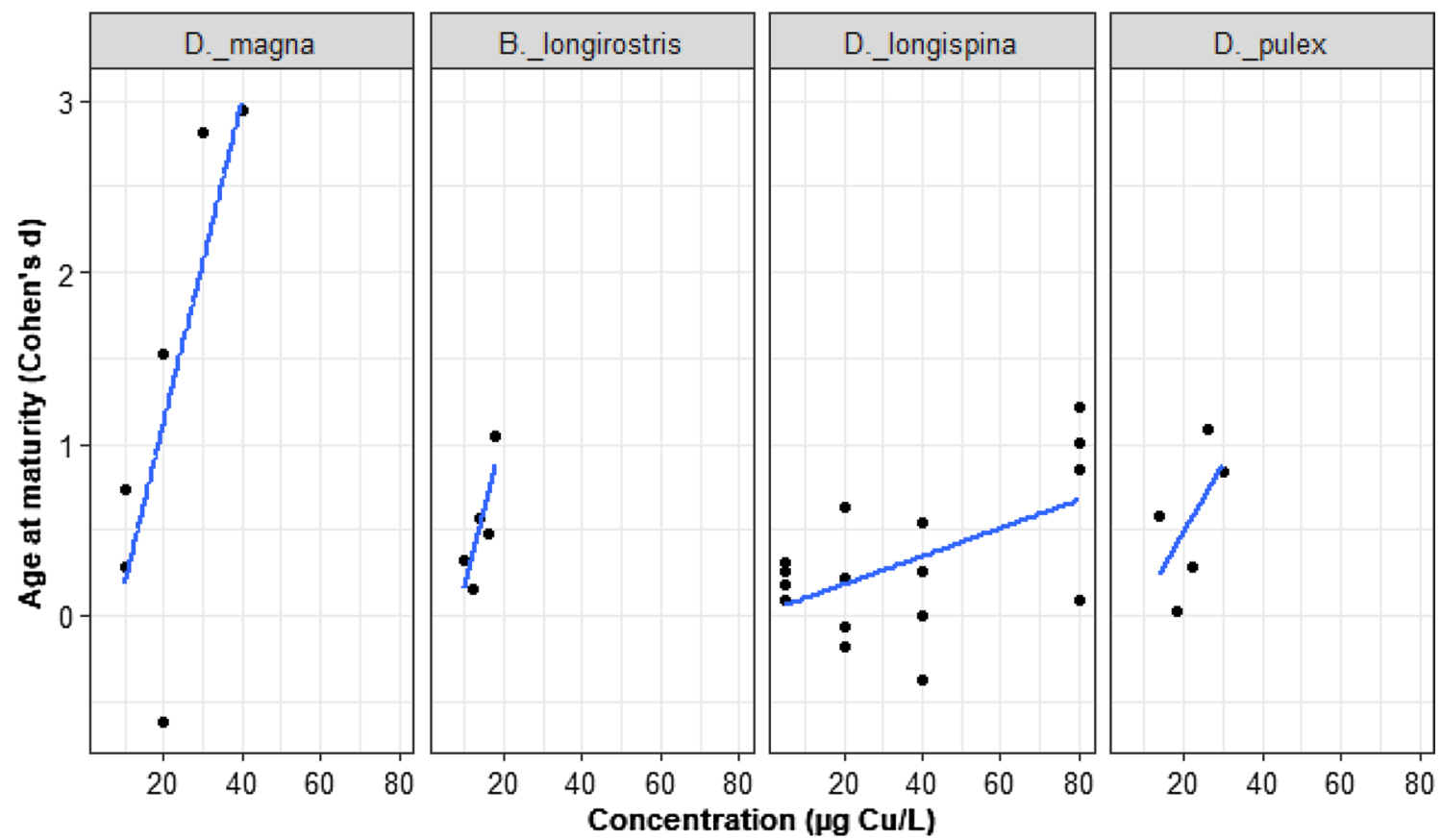

Fig. 4 The maturation age response of four species of Cladocera exposed to nominal sublethal concentrations of $\mathrm{Cu}$. The black dots represent $d$ values, $n=41$. All species are compared to the reference species (D. magna)
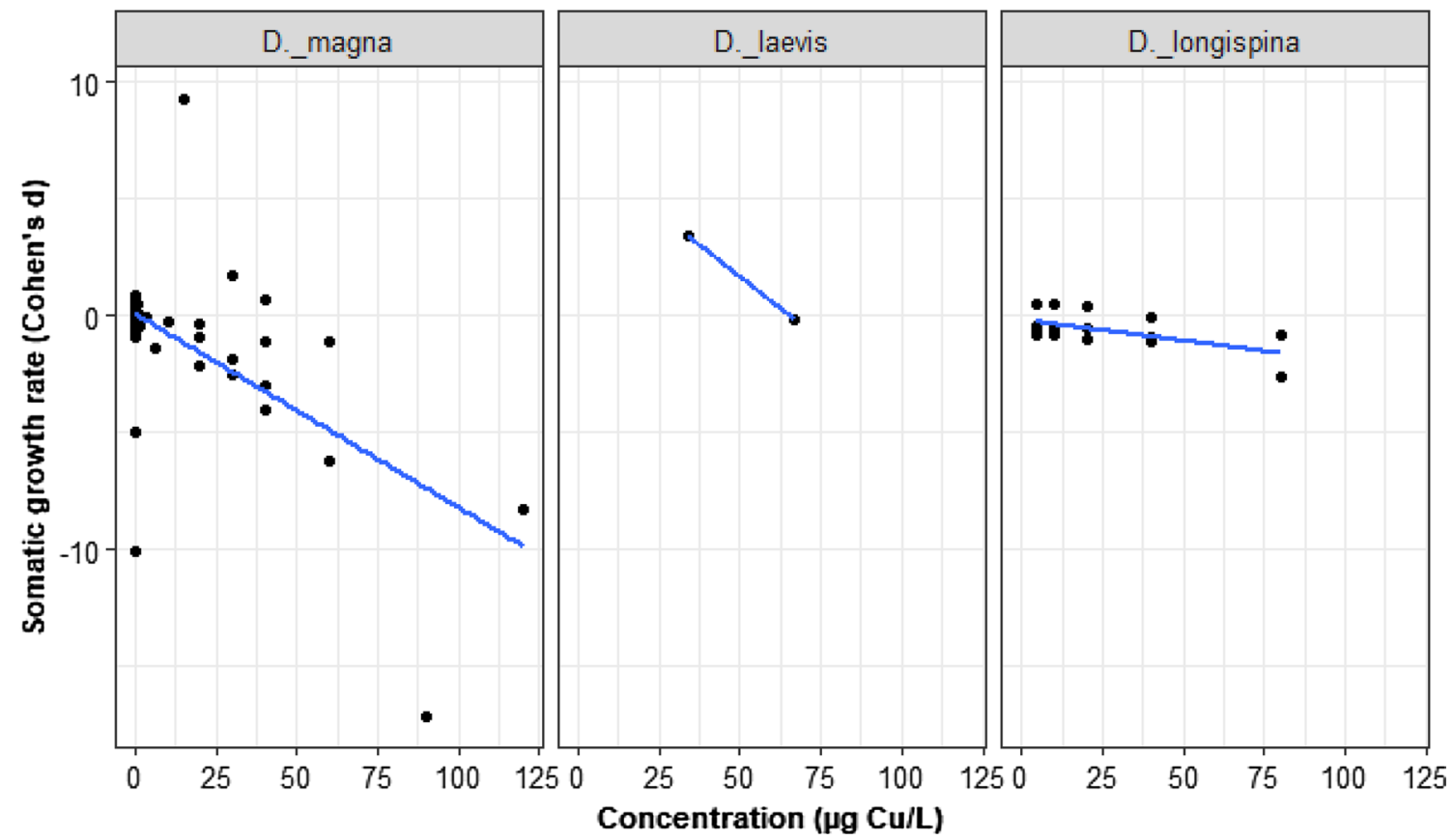

Fig. 5 The somatic growth rate response of Daphnia spp. to sublethal concentrations of $\mathrm{Cu}$ (nominal). The black dots represent $d$ values, $n=69$. All species are compared to the reference species (D. magna)

\section{Cadmium-Age at Maturity}

Data on $\mathrm{Cd}$ and maturation age came from two studies representing 41 cases in two species: D. magna and
M. macleayi. The effect of $\mathrm{Cd}$ concentration on age at maturity did not depend on species (Fig. 7; LRT $=0.17$, $p=0.68$ ). For D. magna, Cd delayed on average the 

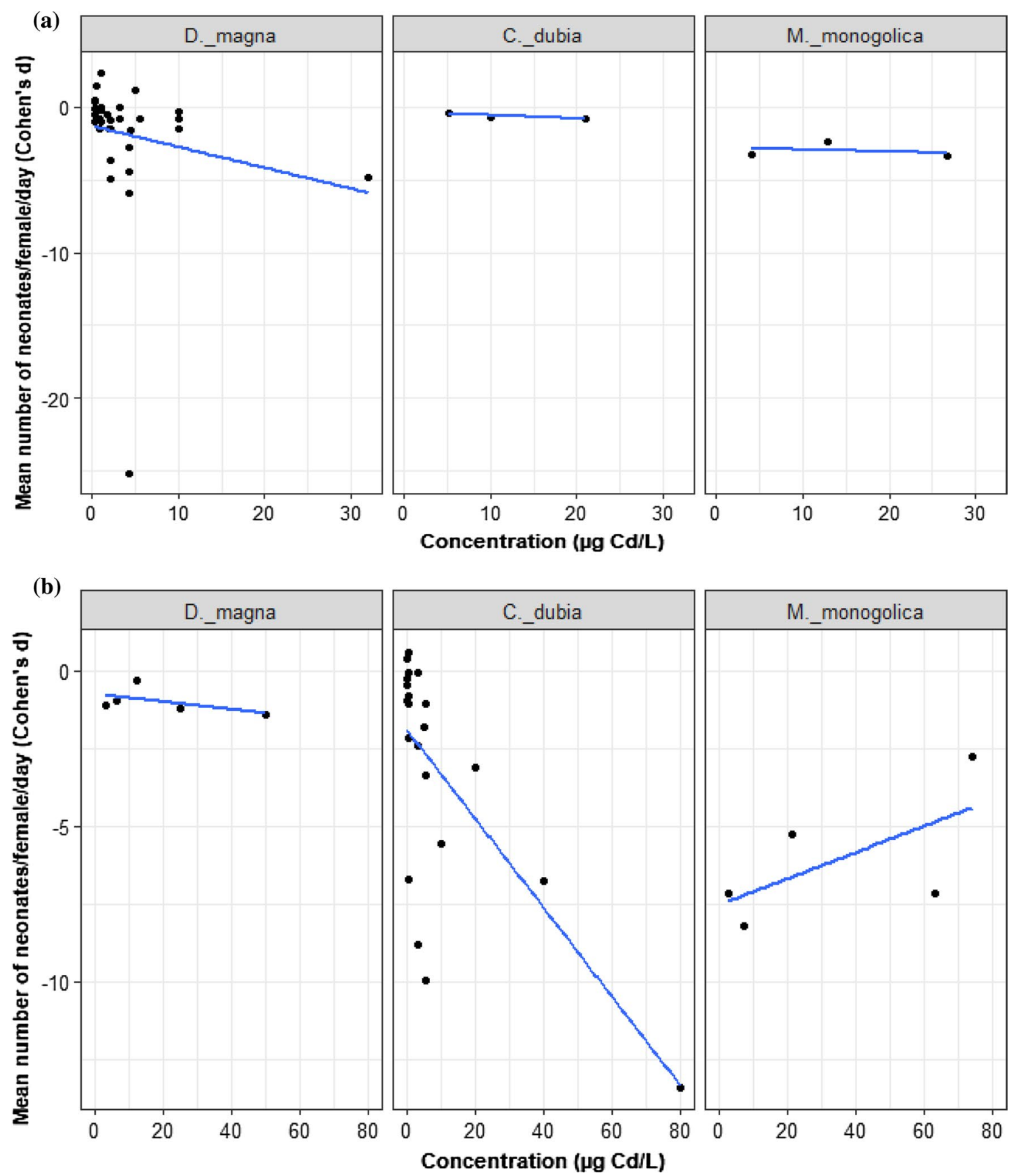

Fig. 6 Mean number of neonates produced per female per day of three species of Cladocera exposed to $\mathbf{a} \leq 40 \mu \mathrm{g} / \mathrm{L}$ nominal aqueous concentrations of $\mathrm{Cd}, n=40, \mathbf{b}>40 \mu \mathrm{g} / \mathrm{L}$ nominal dietary concentra- tions of Cd, $n=32$. The black dots represent $d$ values. All species are compared to the reference species (D. magna)

\section{Cadmium-Growth Rate}

The data on the effects of $\mathrm{Cd}$ on somatic growth rate came from four studies representing 43 trials of three species: D. magna, D. pulex, and M. macleayi. The effect of $\mathrm{Cd}$ concentration on somatic growth rate varied by species (Fig. 8; LRT $=10.77, p=0.0046$ ). There was no effect of 


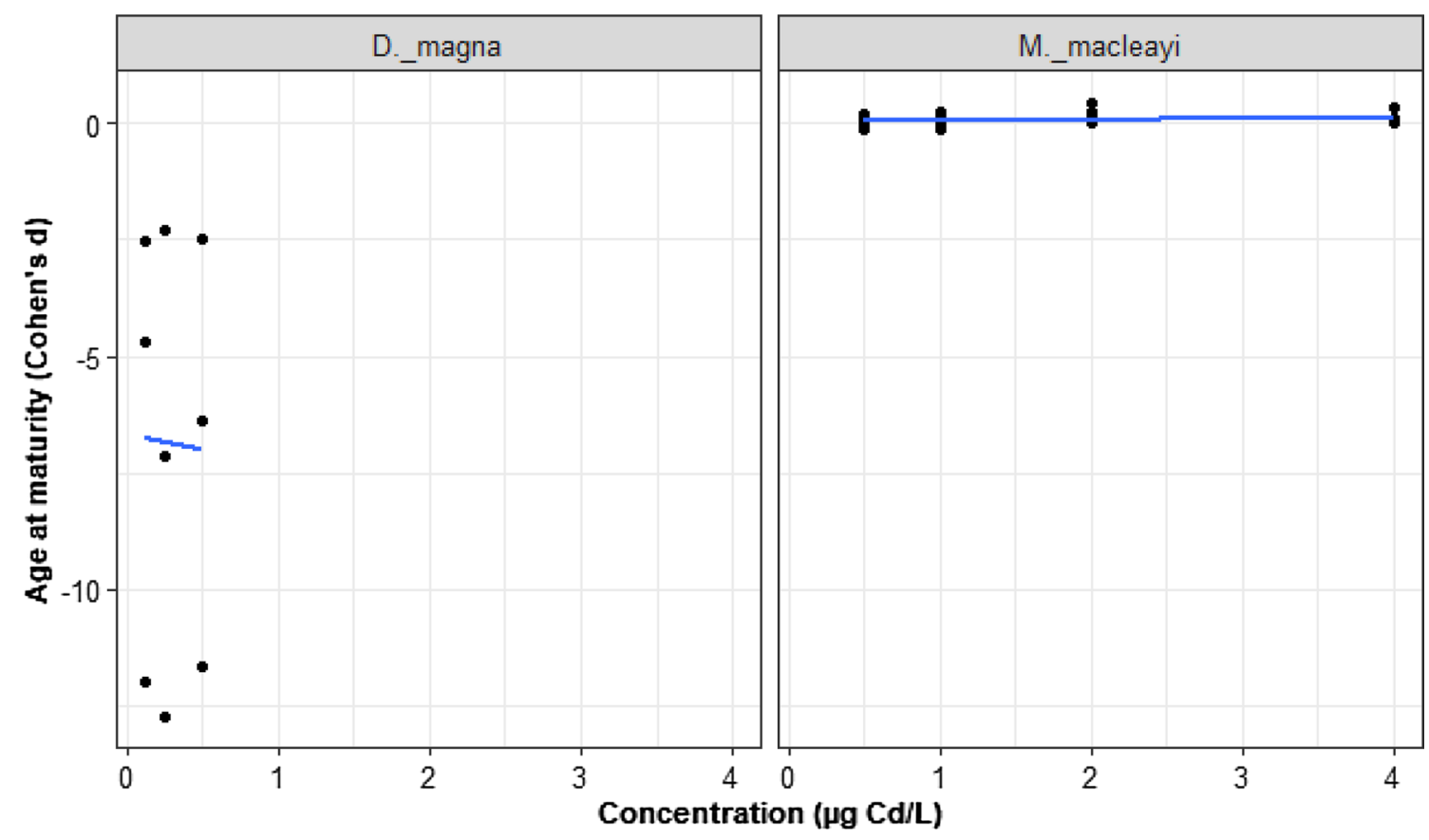

Fig. 7 Sublethal effect of nominal Cd on maturation age of species of Cladocera. The black dots represent $d$ values, $n=41$. Species are compared to the reference species (D. magna)
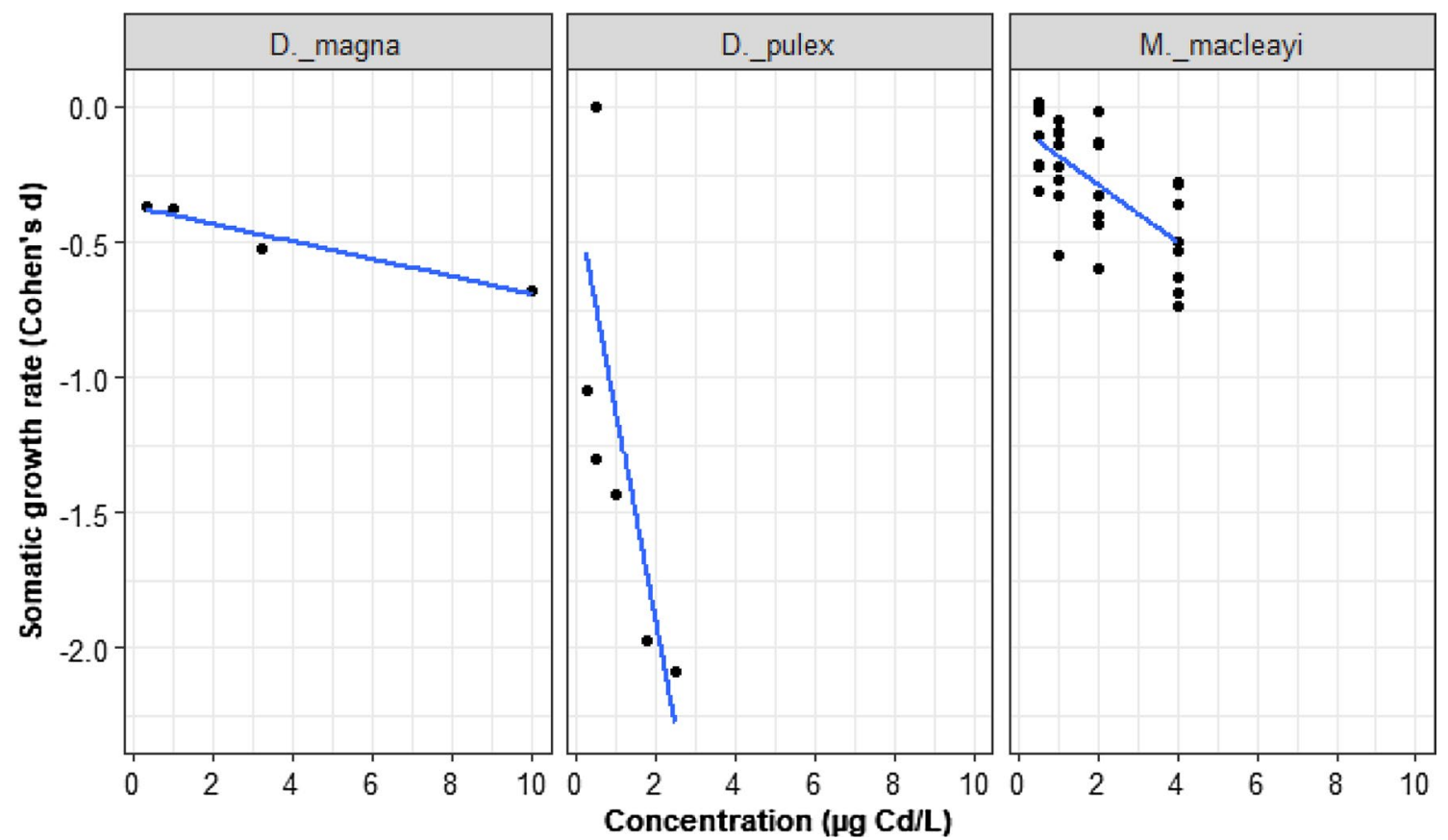

Fig. 8 The mean somatic growth rate for D. magna, D. pulex, and M. macleayi in response to nominal Cd. The black dots represent $d$ values, $n=43$. All species are compared to the reference species (D. magna)

Cd concentrations on D. magna somatic growth (D. magna slope $=-0.03, z=-0.38, p=0.71$, intercept $=-0.37$, $z=-0.83, p=0.41)$. The effect of $\mathrm{Cd}$ on growth in $M$. maclaeyi was indistinguishable from $D$. magna (gradient change from D. magna $=-0.07, z=-0.82, p=0.408$ ). The negative effect of $\mathrm{Cd}$ concentration on $D$. pulex was 
substantially stronger than on $D$. magna (gradient change from D. magna $=-0.88, z=-3.26, p=0.001)$.

\section{Copper and Cadmium-Water Hardness}

According to the literature, water hardness levels (WH) (i.e., soft, moderate and hard) range between 40 and $300 \mathrm{mg} / \mathrm{L}$ as calcium carbonate $(\mathrm{CaCO} 3)$. We asked for these species and trials whether the interaction between $\mathrm{Cu}$ or $\mathrm{Cd}$ concentration and species varied by WH. We constructed four models to evaluate this hypothesis. Model 1 was our full model with main effects of WH, species and metal, 2-way interactions, and the 3-way interaction. Model 2 removed the 3 -way interaction. Model 3 removed both the 3 -way interaction and the 2-way interactions with WH. Model 4 was the core model from all analyses above that include only the metal, species, and metal*species interaction (i.e., no effect of WH). Comparing M1 to M2 via a LRT tested the 3-way interaction. If this was not significant, we compared M2 to M3 via a LRT to test for interactions between $\mathrm{WH}$ and $\mathrm{Cu}$ or WH and species. In the absence of these interactions, comparing M3 to M4 tested for a simple additive effect of WH. We found no evidence to support the effect of WH on the interaction between $\mathrm{Cu}$ and species (7 studies representing 130 trials and 2 species; D. magna and C. dubia; M3 vs. M4: LRT $=2.44$ and $p=0.12$; Fig. 9a). We found no evidence to support the effect of $\mathrm{WH}$ on the interaction between $\mathrm{Cd}$ and species ( 3 studies and 30 trials, D. magna only; M3 vs. M4: $\mathrm{LRT}=2.73, p=0.097$; Fig. 9b).

\section{Copper and Cadmium-Exposure Duration}

We analysed 7 studies and a total of 113 trials that quantified the impact of exposure duration and $\mathrm{Cu}$ on reproduction. Data were only available on $D$. magna exposed to sublethal concentrations of $\mathrm{Cu}$ over two exposure periods: 0-14 and 14-21 (our reference duration) day trials. We found that the effect of $\mathrm{Cu}$ concentration on D. magna reproduction did not differ by test duration (Fig. 10a; LRT $=0.001, p=0.97$ ). The 21-day exposure had no effect on the toxicity of $\mathrm{Cu}$ (slope $=-0.04, z=-7.99, p=0.11$, intercept $=0.51, z=1.1$, $p=0.27)$. The effect of $\mathrm{Cu}$ on reproduction over 14 days was not different from the reference duration (difference in intercept to the reference $=0.36, z=0.99, p=0.32$ ).

In contrast, 4 studies represented 34 trials that quantified the impact of exposure duration and Cd concentration on reproduction. Three test periods were examined for D. magna: 0-14, 14-21 (our reference duration), and 21-45 days exposure. The effect of Cd concentration on D. magna reproduction varied by test duration (Fig. 10b; LRT $=29.17, p=0.0001$ ). Increasing Cd concentration decreased reproduction over 21 days of exposure (slope $=-1.08, z=-5.38, p=0.0001$ ). The 45-day exposure was indistinguishable from the reference (gradient change to the reference $=0.73, z=3.41, p=0.0007$ ). However, 14-day exposure was not affected the toxicity of $\mathrm{Cd}$ (gradient change to the reference $=0.28, z=0.77, p=0.44$ ).

\section{Discussion}

Cladocerans, and particularly Daphnia species, are classic test organisms for evaluating the sublethal effects of metals, which globally represent a serious problem to the aquatic food chain and water quality (Sarma and Nandini 2006; Altshuler et al. 2011; Martins et al. 2017). The sublethal levels of metals have received a great deal of attention, because they cause a range of ecotoxicological effects on those species. However, the importance of species specificity in understanding responses to contaminants remains challenging. Therefore, the main objective of this analysis was to assess quantitatively whether the effects of $\mathrm{Cu}$ and $\mathrm{Cd}$ on life history traits varies among species of Cladocera. Because D. magna is the most common test species, we were able to evaluate by direct comparison whether other species are more or less sensitive to $\mathrm{Cu}$ and $\mathrm{Cd}$ (e.g., whether D. magna can be considered representative). Furthermore, the selected parameters for this analysis-reproduction and somatic growth rate-are considered to be sensitive to sublethal exposure of contaminant.

Many laboratory reports have showed that the effect of contaminants or other stressors vary across species of aquatic organisms (Brix et al. 2001; Griffitt et al. 2008). However, this analysis is the first to have assessed the ecological effects of $\mathrm{Cu}$ and $\mathrm{Cd}$ across different species of Cladocera-the dominant test species in environmental monitoring and ecotoxicology. Recent meta-analysis studies have assessed the effect of contaminants on different biological levels, including species. For example, O’Brien and Keough (2014) suggest that we may expect substantial variation in life history response responses to a range of contaminants, driven by identity of contaminant, the identity of organism (taxa), and the scale of biological organization at which assessment is made (individuals, population, and community). A meta-analysis using 216 studies on the effect of toxic pollutants on marine communities also detected a strong reduction in species richness (Johnston and Roberts 2009). Furthermore, Jan Hendriks et al. (2005) and Blanar et al. (2009) detected via meta-analysis that the response to aquatic pollutants vary by population and community levels (crustaceans and parasites).

\section{The Influence of Metals on Life History Traits}

Our systematic review supports theory on the sublethal effect of $\mathrm{Cu}$ and $\mathrm{Cd}$ across traits/species. The analysis 

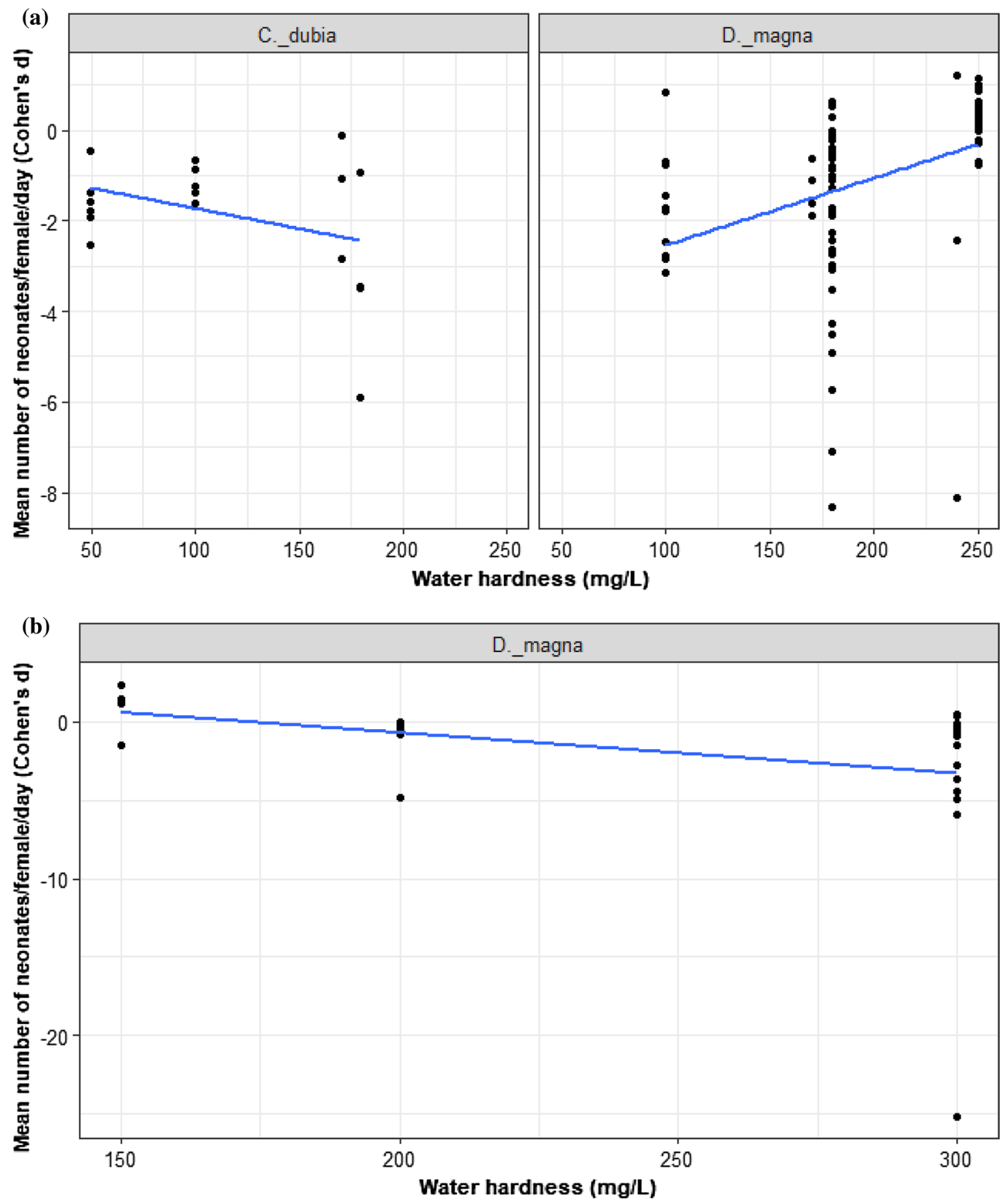

Fig. 9 Water hardness effect on the toxicity of $\mathbf{a ~ C u}, n=130$; $\mathbf{b ~ C d}, n=30$ for Cladocera species reproduction. The black dots represent $d$ values where species are compared with the reference species (D. magna)

demonstrated that overall $\mathrm{Cu}$ and $\mathrm{Cd}$ reduce reproduction, increase the age at maturity, and reduce growth, as expected by theory linked to their mode of action. However, there was substantial variation among species and D. magna was not uniformly the most responsive species.

We found that the effect of $\mathrm{Cu}$ on reproduction (only aqueous delivery), maturation age, and somatic growth rate depended on species identity. Likewise, the effects of $\mathrm{Cd}$ on reproduction (only dietary delivery) and somatic growth rate also depend on species identity. In many cases, the dominant test species $D$. magna often was quite resistant to nominal metal concentrations up to $120 \mu \mathrm{g} / \mathrm{L} \mathrm{Cu}$ and $40 \mu \mathrm{g} / \mathrm{L}$ $\mathrm{Cd}$. Furthermore, D. longispina reproductive response to aqueous $\mathrm{Cu}$ and $D$. magna response to dietary $\mathrm{Cu}$ were 

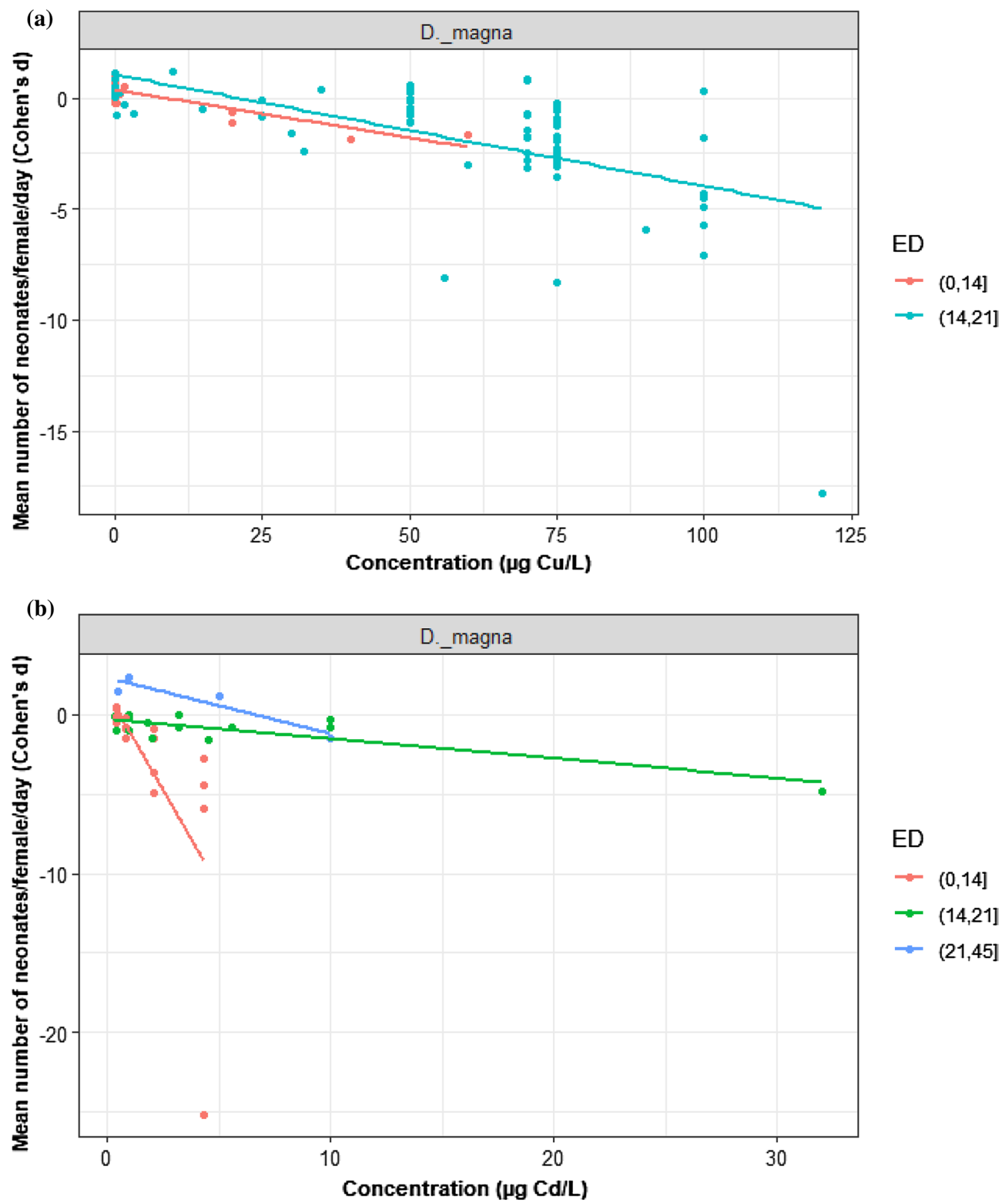

Fig. 10 Effect of exposure duration (ED) on the toxicity of a $\mathrm{Cu}, n=113$; $\mathbf{b} \mathrm{Cd}, n=34$ for $D$. magna reproduction. The black dots represent $d$ values where exposure duration compared with the reference duration 14-21

positive. Our data indicate that reproduction is likely the most sensitive endpoint showing strong responses to both metals among species. Life history endpoints may respond differently to the same stressor or a combination of stressors. For example, Bednarska et al. (2009) found that the reproduction of adult ground beetles was most sensitive to nickel concentrations at low and high temperatures $\left(10\right.$ and $\left.25^{\circ} \mathrm{C}\right)$, but the survival was less affected by the combined effect of $\mathrm{Ni}$ and chlorpyriphos at both temperatures. Furthermore, Laskowski et al. (2010) conducted a meta-analysis on the interactions between toxic chemicals and natural environmental factors across a range of vertebrates and invertebrates species (including metals and D. magna), finding that the effects of toxicants on organisms may differ depending on 
external factors. Whilst, Vijver et al. (2011) suggested via meta-analysis that the effect types (additive, antagonistic, and synergistic) were significantly different across toxicological endpoints and combinations of $\mathrm{Cu}, \mathrm{Cd}$, and $\mathrm{Zn}$.

Our quantitative review highlights that species vary in their sensitivity to metals. This can arise for several reasons. Mode of actions vary, the effects of pollutants can be regulated through different physiological pathways that may be species-specific, and we also expect variation due to choice of genotype used in the studies (Baird et al. 1990; Brix et al. 2001; Barata et al. 2004; Bossuyt and Janssen 2005). While it was impossible in our analysis of published data to deduce whether the same or different genotypes were being used, within species genetic variation is also likely important to consider at population and community levels. Overall, the limited number of studies reporting appropriate information for meta-analyses (sample size, means and standard deviation/error) (Furukawa et al. 2006), combined with missing detail on genotype identity, means that there is ample opportunity to pursue more rigorous assessment of these sources of variation and their impact on specificity of responses.

\section{The influence of the experimental factors on individuals' responses to metals}

Given natural variation in $\mathrm{pH}$, water hardness, and other environmental factors in ponds and lakes, and the theoretical expectation that these factors may influence bioavailability, we also explored whether variation in experimental conditions influenced experimental effects of $\mathrm{Cu}$ and $\mathrm{Cd}$ concentrations. According to data available in this analysis, for both metals, variation among trials did not appear to arise from variation in water hardness. This correspond with the study of De Schamphelaere and Janssen (2004b) who found that water hardness had no effect on the chronic toxicity of $\mathrm{Cu}$ in D. magna. Keithly et al. (2004) showed that chronic toxicity of Ni was less dependent on hardness in C. dubia than acute toxicity. Our results showed that test duration had no pronounced effects on the chronic toxicity of $\mathrm{Cu}$, suggesting perhaps rapid acclimation. However, under $\mathrm{Cd}$ exposure, $D$. magna reproduction was affected by test duration.

Our data on water hardness contrasts with what may be suggested by simply looking at results (vote counting) from the published literature. Many consider water hardness to be a crucial factor affecting metals toxicity; many reports showed that the high levels of hardness may decrease the toxicity of $\mathrm{Cu}$ and $\mathrm{Cd}$ (Winner 1986; Heijerick et al. 2003; Wang et al. 2016). However, other works indicated that heavy metals are more toxic in soft water (Ebrahimpour et al. 2010; Taylor et al. 2000). Furthermore, the effect of water chemistry on metals toxicity may be varied across the acute and chronic exposures (De Schamphelaere and Jansen 2004c). For example, Belanger and Cherry (1990) found that $\mathrm{pH}$ had negligible influences on the toxicity of $\mathrm{Cu}$ to reproduction of $C$. dubia. However, increasing $\mathrm{pH}$ caused a decrease in the acute toxicity (48-h mortality). Moreover, the effect of water chemistry variables on metals toxicity may show different responses under the same experimental conditions. Kozlova et al. (2009) found that sodium, potassium, and chloride ions did not affect the toxicity $\mathrm{Ni}$ on $D$. pulex, whereas $\mathrm{pH}$ effect on Ni toxicity varied in presence of $\mathrm{HCO}_{3}$. Similarly, the study of De Schamphelaere and Janssen $(2004 \mathrm{c})$ showed that dissolved organic carbon (DOC) and $\mathrm{pH}$ had a significant impact on chronic toxicity of $\mathrm{Cu}$ to D. magna, but water hardness did not.

Meta-analytic methods provide substantially more reliable insights into the effects across studies. While our results show limited effects, it is important to recognize that our data are a subset of all studies that report sufficient information to include in meta-analyses. A more thorough and standardized reporting of results linked to water hardness and test duration is thus warranted. Our analysis data is not always in line with literature, but the BLM and better availability of data for meta-analyses in the future will help reconcile these issues.

\section{Conclusions and Recommendations}

This analysis is the first meta-analytic consideration of the ecological effects of $\mathrm{Cu}$ and $\mathrm{Cd}$ concentration across different species of Cladocera. The data highlight several species' specific responses to the sublethal concentrations of both metals and several traits that, on average, appear tolerant to metals in some species. The substantial omission of numerous studies due to incomplete reporting of means, standard deviations/errors, and sample size is sobering given the importance of drawing generalized conclusions from test species. Detailed meta-analyses (and associated effective reporting of data) on water quality parameters, such as hardness, $\mathrm{pH}$, and dissolved organic components (DOC), are needed to elucidate the role of water chemistry on the toxicity of metals across different biological organizations.

Acknowledgements The authors thank E. Hansson and S. Roccuzzo for constructive comments. This paper is a part of an ecotoxicological research on metals mixtures/PhD degree at the University of Sheffield, with financial support provided by The Ministry of Higher Education and Scientific Research, Iraq.

Data Availability Supplementary data associated with this article can be found at https://figshare.com/s/e8cd00ea26b6446fc398.

\section{Compliance with Ethical Standards}

Conflict of interest The authors have no conflicts of interest associated with this publication. 
Open Access This article is distributed under the terms of the Creative Commons Attribution 4.0 International License (http://creativeco mmons.org/licenses/by/4.0/), which permits unrestricted use, distribution, and reproduction in any medium, provided you give appropriate credit to the original author(s) and the source, provide a link to the Creative Commons license, and indicate if changes were made.

\section{References}

Agra AR, Soares AMVM, Barata C (2011) Life-history consequences of adaptation to pollution. Daphnia longispina clones historically exposed to copper. Ecotoxicology 20:552-562

Al-Reasi HA, Smith DS, Wood CM (2012) Evaluating the ameliorative effect of natural dissolved organic matter (DOM) quality on copper toxicity to Daphnia magna: improving the BLM. Ecotoxicology 21:524-537

Altshuler I, Demiri B, Xu S, Constantin A, Yan ND, Cristescu ME (2011) An integrated multi-disciplinary approach for studying multiple stressors in freshwater ecosystems: Daphnia as a model organism. Integr Comp Biol 51:623-633

Bae J-S, Freeman HS (2007) Aquatic toxicity evaluation of coppercomplexed direct dyes to the Daphnia magna. Dyes Pigment 73:126-132

Baird DJ, Barber I, Calow P (1990) Clonal variation in general responses of Daphnia magna Straus to toxic stress. I. Chronic life history effects. Funct Ecol 4:399-407

Barata C, Baird DJ (2000) Determining the ecotoxicological mode of action of chemicals from measurements made on individuals: results from instar-based tests with Daphnia magna Straus. Aquat Toxicol 48:195-209

Barata C, Baird DJ, Miňarro A, Soares AMVM (2000) Do genotype responses always converge from lethal to nonlethal toxicant exposure levels? Hypothesis tested using clones of Daphnia magna straus. Environ Toxicol Chem 19:2314-2322

Barata C, Porte C, Baird DJ (2004) Experimental designs to assess endocrine disrupting effects in invertebrates: a review. Ecotoxicology 13:511-517

Bednarska AJ, Portka I, Kramarz PE, Laskowski R (2009) Combined effect of environmental pollutants (nickel, chlorpyrifos) and temperature on the ground beetle, Pterostichus oblongopunctatus (Coleoptera: Carabidae). Environ Toxicol Chem 28:864-872

Belanger SE, Cherry DS (1990) Interacting effects of $\mathrm{pH}$ acclimation, $\mathrm{pH}$, and heavy metals on acute and chronic toxicity to Ceriodaphnia dubia (Cladocera). J Crustacean Biol 10:225-235

Bellavere C, Gorbi J (1981) A comparative analysis of acute toxicity of chromium, copper and cadmium to Daphnia magna, Biomphalaria glabrata, and Brachydanio rerio. Environ Technol Lett 2:119-128

Blanar CA, Munkittrick KR, Houlahan J, MacLatchy DL, Marcogliese DJ (2009) Pollution and parasitism in aquatic animals: a metaanalysis of effect size. Aquat Toxicol 93:18-28

Bodar CWM, van Leeuwen CJ, Voogt PA, Zandee DI (1988a) Effect of cadmium on the reproduction strategy of Daphnia magna. Aquat Toxicol 12:301-310

Bodar CWM, Van Der Sluis I, Vooct PA, Zandee DI (1988b) Effect of cadmium on consumption, assimilation and biochemical parameters of Daphnia magna: possible implications for reproduction. Comp Biochem Physiol 90C:341-346

Bossuyt BTA, Janssen CR (2004) Influence of multigeneration acclimation to copper on tolerance, energy reserves and homeostasis of Daphnia magna straus. Environ Toxicol Chem 23:2029-2037

Bossuyt BTA, Janssen CR (2005) Copper regulation and homeostasis of Daphnia magna and Pseudokirchneriella subcapitata: influence of acclimation. Environ Pollut 136:135-144
Bossuyt BTA, De Schamphelaere KAC, Janssen CR (2004) Using the biotic ligand model for predicting the acute sensitivity of cladoceran dominated communities to copper in natural surface waters. Environ Sci Technol 38:5030-5037

Brix KV, Deforest DK, Adams WJ (2001) Assessing acute and chronic copper risks to freshwater aquatic life using species sensitivity distribution for different taxonomic groups. Environ Toxicol Chem 20(8):1846-1856

Bui T-KL, Do-Hong LC, Dao T-S, Hoang TC (2016) Copper toxicity and the influence of water quality of Dongnai River and Mekong River waters on copper bioavailability and toxicity to three tropical species. Chemosphere 144:872-878

Cairns J Jr (1983) Are single species toxicity tests alone adequate for estimating environmental hazard? Hydrobiologia 100:47-57

Chandini T (1989) Survival, growth and reproduction of Daphnia carinta (Crustacea: Cladocera) exposed to chronic cadmium stress at different food (Chlorella) level. Environ Pollut 60:29-45

Clifford M, McGeer JC (2010) Development of a biotic ligand model to predict the acute toxicity of cadmium to Daphnia pulex. Aquat Toxicol 98:1-7

Cooper NL, Bidwell GR, Kumar A (2009) Toxicity of copper, lead, and zinc mixtures to Ceriodaphnia dubia and Daphnia carinata. Ecotoxicol Environ Saf 72:1523-1528

Dao T-S, Le V-N, Bui B-T, Dinh KV, Wiegand C, Nguyen T-S, Dao C-T, Nguyen V-D, To T-H, Nguyen L-S-P, Vo T-G, Vo T-M-C (2017) Sensitivity of a tropical micro-crustacean (Daphnia lumholtzi) to trace metals tested in natural water of the Mekong River. Sci Total Environ 574:1360-1370

Dave G (1984) Effects of copper on growth, reproduction, survival and hemoglobin in Daphnia magna. Comp Biochem Physiol 78C:439-443

De Coen WM, Janssen CR (1997) The use of Biomarkers in Daphnia magna toxicity testing II. Digestive enzyme activity in Daphnia magna exposed to sublethal concentrations of cadmium, chromium and mercury. Chemosphere 35:1053-1067

De Coen WM, Janssen CR (1998) The use of biomarkers in Daphnia magna toxicity testing. Hydrobiologia 367:199-209

de Oliveira-Filho EC, Lopes RM, Paumgartten FJR (2004) Comparative study on the susceptibility of freshwater species to copperbased pesticides. Chemosphere 56:369-374

De Schamphelaere KAC, Janssen CR (2004a) a) Effects of chronic dietary copper exposure on growth and reproduction of Daphnia magna. Environ Toxicol Chem 23:2038-2047

De Schamphelaere KAC, Janssen CR (2004b) b). Development and field validation of a biotic ligand model predicting chronic copper toxicity to Daphnia magna. Environ Toxicol Chem 23:1365-1375

De Schamphelaere KAC, Janssen CR (2004c) c). Effects of dissolved organic carbon concentration and source, $\mathrm{pH}$ and water hardness on chronic toxicity of copper to Daphnia magna. Environ Toxicol Chem 23:1115-1122

De Schamphelaere KAC, Vasconcelos FM, Tack FMG, Aallen HE, Janssen CR (2004) Effect of dissolved organic matter source on acute copper toxicity to Daphnia magna. Environ Toxicol Chem 23:1248-1255

De Schamphelaere KAC, Heijerick DG, Janssen CR (2006) Crossphylum comparison of a chronic biotic ligand model to predict chronic toxicity of copper to a freshwater rotifer, Brachionus calyciflorus (Pallas). Ecotoxicol Environ Saf 63:189-195

De Schamphelaere KAC, Forrez I, Dierckens K, Sorgeloos P, Janssen CR (2007) Chronic toxicity of dietary copper to Daphnia magna. Aquat Toxicol 81:409-418

Dedourge-Geffard O, Palais F, Biagianti-Risbourg S, Geffard O, Geffard A (2009) Effects of metals on feeding rate and digestive enzymes in Gammarus fossarum: an in situ experiment. Chemosphere 77:1569-157116 
Demirak A, Yilmaz F, Tuna AL, Ozdemir N (2006) Heavy metals in water, sediment and tissues of Leuciscus cephalus from a stream in southwestern Turkey. Chemosphere 6:1451-1458

Di Toro DM, Allen HE, Bergman H, Meyer JS, Paquin PR, Santore CS (2001) Biotic ligand model of the acute toxicity of metals. 1. Technical basis. Environ Toxicol Chem 20:2383-2396

Ebrahimpour M, Alipour H, Rakhshah S (2010) Influence of water hardness on acute toxicity of copper and zinc on fish. Toxicol Ind Health 26(6):361-365

Esbaugh AJ, Brix KV, Mager EM, De Schamphelaere K, Grosell M (2012) Multi-linear regression analysis, preliminary biotic ligand modeling, and cross species comparison of the effects of water chemistry on chronic lead toxicity in invertebrates. Comp Biochem Physiol Part C 155:423-431

Fernández-Gonzáles MA, Gonzáles-Barrientos J, Carter MJ, RamosJiliberto R (2011) Parent-to-offspring transfer of sublethal effects of copper exposure: metabolic rate and life-history traits of Daphnia. Rev Chil Hist Nat 84:195-201

Ferrando MD, Andreu E (1993) Feeding behavior as an index of copper stress in Daphnia magna and Brachionus calyciflorus. Comp Biochem Physiol 106C:327-331

Furukawa TA, Barbui C, Cipriani A, Brambilla P, Watanabe N (2006) Imputing missing standard deviations in meta-analyses can provide accurate results. J Clin Epidemiol 59:7-10

Gama-Flores JL, Sarma SSS, Nandini S (2006) Effect of cadmium level and exposure time on the competition between zooplankton species Moina macrocopa (Cladocera) and Brachionus calyciflorus (Rotifera). J Environ Sci Health, Part A 41:1057-1070

Giusto A, Ferrari L (2014) Biochemical responses of ecological importance in males of the austral South America amphipod Hyalella curvispina Shoemaker, 1942 exposed to waterborne cadmium and copper. Ecotoxicol Environ Saf 100:193-200

Griffitt RJ, Luo J, Gao J, Bonzongo J-C, Barber DS (2008) Effect of particle composition and species on toxicity of metallic nanomaterials in aquatic organisms. Environ Toxicol Chem 27(9):1972-1978

Gusso-Choueri PK, Choueri RB, Lombardi AT, Melão MGG (2012) Effects of dietary copper on life-history traits of a tropical freshwater cladoceran. Arch Environ Contam Toxicol 62:589-598

Handy RD, Eddy FB, Baines H (2002) Sodium-dependent copper uptake across epithelia: a review of rationale with experimental evidence from gill and intestine. Biochim Biophys Acta 1566:104-115

Heijerick DG, Janssen CR, De Coen WM (2003) The combined effects of hardness, $\mathrm{pH}$, and dissolved organic carbon on the chronic toxicity of $\mathrm{Zn}$ to D. magna: development of a surface response model. Arch Environ Contam Toxicol 44:210-217

Hoang TC, Klaine SJ (2007) Influence of organism age on metal toxicity to Daphnia magna. Environ Toxicol Chem 26:1198-1204

International Agency for Research on Cancer of USA (1997) Berylium, cadmium, mercury and exposures in the glass manufacturing industry. Summary of data reported and evaluation. IARC Monographs on the Evaluation of Carcinogenic Risks to Humans

Jan Hendriks A, Maas-Diepeveen JLM, Heugens EHW, van Straalen NM (2005) Meta-analysis of intrinsic rates of increase and carrying capacity of populations affected by toxic and other stressors. Environ Toxicol Chem 24:2267-2277

Jing G, Li Y, Xie L, Zhang R (2006) Metal accumulation and enzyme activities in gills and digestive gland of pearl oyster (Pinctada fucata) exposed to copper. Comp Biochem Physiol 144:1841-1890

Johnston EL, Roberts DA (2009) Contaminants reduce the richness and evenness of marine communities: a review and meta-analysis. Environ Pollut 157:1745-1752
Katranitsas A, Castritsi-Catharios J, Persoone G (2003) The effects of a copper-based antifouling paint on mortality and enzymatic activity of a non-target marine organism. Mar Pollut Bull 46:1491-1494

Keithly J, Brooker JA, Deforest DK, Wu BK, Brix KV (2004) Acute and chronic toxicity of nickel to a cladoceran (Ceriodaphnia dubia) and an amphipod (Hyalella azteca). Environ Toxicol Chem 23:691-696

Khangarot BS, Rathore RS (2003) Effects of copper on respiration, reproduction, and some biochemical parameters of water flea Daphnia magna Straus. Bull Environ Contam Toxicol 70:112-117

Kim H, Yim B, Bae C, Lee Y-M (2017) Acute toxicity and antioxidant responses in the water flea Daphnia magna to xenobiotics (cadmium, lead, mercury, bisphenol A, and 4-nonylphenol). Toxicol Environ Health Sci 9:41-49

Knops M, Altenburger R, Segner H (2001) Alterations of physiological energetics, growth and reproduction of Daphnia magna under toxicant stress. Aquat Toxicol 53:79-90

Koivisto S, Ketolab M, Walls M (1992) Comparison of five cladoceran species in short- and long-term copper exposure. Hydrobiologia 248:125-136

Kozlova T, Wood CM, McGeer JC (2009) The effect of water chemistry on the acute toxicity of nickel to the cladoceran Daphnia pulex and the development of a biotic ligand model. Aquat Toxicol 91:221-228

Lampert W (2006) Daphnia: model herbivore, predator and prey. Pol J Ecol 54:607-620

Laskowski R, Bednarska AI, Kramarz PE, Loureiro S, Scheil V, Kudlek J, Holmstrup M (2010) Interactions between toxic chemicals and natural environmental factors-a meta-analysis and case studies. Sci Total Environ 408:3763-3774

Letelier ME, Lepe AM, Faundez M, Salazar J, Marına R, Aracena P, Speisky H (2005) Possible mechanisms underlying copperinduced damage in biological membranes leading to cellular toxicity. Chem Biol Interact 151:71-82

Long KE, Van Genderen EJ, Klaine SJ (2004) The effects of low hardness and $\mathrm{pH}$ on copper toxicity to Daphnia magna. Environ Toxicol Chem 23:72-75

Lopes I, Baird DJ, Ribeiro R (2004) Genetic determination of tolerance to lethal and sublethal copper concentrations in field populations of Daphnia longispina. Arch Environ Contam Toxicol 46:43-51

Luciana R, Ulises R, Susana G, Horacio T, Ana María G (2014) Effect of metals on Daphnia magna and cladocerans representatives of the Argentinean fluvial littoral. J Environ Biol 35:689-697

Lv X, Huang B, Zhu X, Jiang Y, Chen B, Tao Y, Zhou J, Cai Z (2017) Mechanisms underlying the acute toxicity of fullerene to Daphnia magna: energy acquisition restriction and oxidative stress. Water Res 123:696-703

MacWilliam RA, Baird DJ (2002) Post-exposure feeding depression: A new toxicity endpoint for use in laboratory studies with Daphnia magna. Environ Toxicol Chem 21:1198-1205

Martins C, Jesus FT, Nogueira AJA (2017) The effects of copper and zinc on survival, growth and reproduction of the cladoceran Daphnia longispina: introducing new data in an "old" issue. Ecotoxicology 26:1156-1169

Mountouris A, Voutsas E, Tassios D (2002) Bioconcentration of heavy metals in aquatic environments: the importance of bioavailability. Mar Pollut Bull 44:1136-1141

O'Brien AL, Keough MJ (2014) Ecological responses to contamination: A meta-analysis of experimental marine studies. Environ Pollut 195:185-191

Osenberg CW, Sarnelle O, Cooper SD (1997) Effect size in ecological experiments: the application of biological models in metaanalysis. Am Nat 150:798-812

Pagliarani A, Ventrella V, Trombetti F, Pirini M, Trigari G, Borgatti AR (1996) Mussel microsomal $\mathrm{Na}^{+}, \mathrm{Mg}^{2+}$-ATPase sensitivity to 
waterborne mercury, zinc and ammonia. Comp Biochem Physiol C 113:185-191

Rahbek C (2005) The role of spatial scale and the perception of largescale species-richness patterns. Ecol Lett 8:224-239

Roux DJ, Kempster PL, Truter E, van der Merwe L (1993) Effect of cadmium and copper on survival and reproduction of Daphnia pulex. Water SA 19:269-274

Sandrini JZ et al (2008) Antioxidant responses in the Nereid Laeonereis acuta (Annelida, Polychaeta) after cadmium exposure. Ecotoxicol Environ Saf 70:115-120

Santore RC, Di Toro DM, Paquin PR, Allen HE, Meyer JS (2001) Biotic ligand model of the acute toxicity of metals. 2. Application to acute copper toxicity in freshwater fish and daphnia. Environ Toxicol Chem 20(10):2397-2402

Sarma SSS, Nandini S (2006) Review of recent ecotoxicological studies on cladocerans. J Environ Sci Health, Part B 41:1417-1430

Shanker AK (2008) Mode of action and toxicity of trace elements. In: Prasad MNV (ed) Trace elements as contaminants and nutrients: consequences in ecosystems and human health. Wiley, Hoboken, pp 525-555

Shuhaimi-Othman M, Nadzifah Y, Ahmad AK (2010) Toxicity of copper and cadmium to freshwater fishes. World Acad Sci Eng Technol 65:869-871

Soetaert A, Vandenbrouck T, van der Ven K, Maras M, van Remortel P, Blust R, De Coen WM (2007) Molecular responses during cadmium-induced stress in Daphnia magna: integration of differential gene expression with higher-level effects. Aquat Toxicol $83: 212-222$

Sofyan A, Rosita G, Price DJ, Birge WJ (2007) Cadmium uptake by Ceriodaphnia dubia from different exposures; Relevance to body burden and toxicity. Environ Toxicol Chem 26:470-477

Stephan CE, Mount DL, Hansen DJ, Gentile JH, Chapman GA, Brungs WA (1985) Guidelines for deriving numerical national water quality criteria for the protection of aquatic organisms and their uses, Report \# PB85-227049. Environmental Protection Agency, Washington

Stoddard JL, Harper R (2007) Effects of multi-generational exposure of Daphnia magna to copper. Ph.D. thesis. Huxley College of the Environment, Western Washington University
Stohs SJ, Bagchi D (1995) Oxidative mechanisms in the toxicity of metal ions. Free Radic Biol Med 18:321-336

Stollewerk A (2010) The water flea Daphnia-a 'new' model system for ecology and evolution? J Biol 9:21

Tan Q-G, Wang W-X (2011) Acute toxicity of cadmium in Daphnia magna under different calcium and $\mathrm{pH}$ conditions: importance of influx rate. Environ Sci Technol 45:1970-1976

Taylor LN, McGeer JC, Wood CM, McDonald DG (2000) Physiological effects of chronic copper exposure to rainbow trout (Oncorhynchus mykiss) in hard and soft water: evaluation of chronic indicators. Environ Toxicol Chem 19:2298-2308

R Core Team (2013) R: a language and environment for statistical computing. R Foundation for Statistical Computing, Vienna, Austria. http://www.R-project.org

Viechtbauer W (2010) Conducting meta-analyses in R with the metaphor package. J Stat Softw 36:1-48

Vijver MG, Elliott EG, Peijnenburg WJGM, Snoo De (2011) Response predictions for organisms water-exposed to metal mixtures: a meta-analysis. Environ Toxicol Chem 30:1482-1487

Vilá M, Espinar JL, Hejda M, Hulme PE, Jarošík V, Maron JL, Pergl J, Schaffner U, Sun Y, Pvšek P (2011) Ecological impacts of invasive alien plants: a meta-analysis of their effects on species, communities and ecosystems. Ecol Lett 14:702-708

Waisberg M, Joseph P, Hale B, Beyersmann D (2003) Molecular and cellular mechanisms of cadmium carcinogenesis. Toxicology 192:95-117

Wang YD, Fang J, Leonard SS, Rao KM (2004) Cadmium inhibits the electron transfer chain and induces reactive oxygen species. Free Radic Biol Med 36(11):1434-1443

Wang Z, Yan C, Zhang X (2009) Acute and chronic cadmium toxicity to a saltwater cladoceran Moina monogolica Daday and its relative importance. Ecotoxicology 18:47-54

Wang Z, Meador JP, Leung KMY (2016) Metal toxicity to freshwater organisms as a function of $\mathrm{pH}$ : a meta-analysis. Chemosphere 144:1544-1552

Winner RW (1986) Interactive effect of water hardness and humic acid on the chronic toxicity of cadmium to Daphnia pulex. Aquat Toxicol 8:281-293 